\title{
Research on the Problems in the Construction of Smart Community in China and Its Countermeasures
}

\author{
Wenli Deng \\ School of Political Science and Public Administration \\ University of Electronic Science and Technology of China \\ Chengdu, China
}

\begin{abstract}
The Smart Community is the hot fields of the pilot and application of the smart city in our country, as well as the important direction of the development and construction of future urban community. This paper introduces the concept and characteristics of the Smart Community, analyzes the main problems existing in the construction of the Smart Community in our country and puts forward the corresponding countermeasures.
\end{abstract}

Keywords-Smart Community; characteristics; problems; countermeasures

\section{INTRODUCTION}

The Smart Community is the hot fields of the pilot and application of the smart city in our country, as well as the important direction of the development and construction of future urban community. The construction of Smart Community is beneficial to the aggregation and coordination of various resources in the community, which is conducive to promoting the overall construction of the Smart Community, improving the autonomy and service ability of community, equalizing public services of government and raising the convenience and comfort level of life of community residents. At present, China has encountered some problems in the process of promoting the construction of Smart Community, so only by taking effective measures to solve these problems can we give full play to the function of Smart Community and promote the further development of the harmonious society.

\section{THE CONCEPT AND CHARACTERISTICS OF THE SMART COMMUNITY}

\section{A. The Concept of Smart Community}

The concept of "Smart Community" first appeared in the 1990s, and then with the proposing of concept of smart earth and smart city, the practice of Smart Community began to be carried out in many cities.

In 1992, the Communication International Center of the University of San Diego in the United States formally defined the concept: significantly and fundamentally change the living and working conditions in the region by using advanced information technology, and this change is a change in the nature, rather than incremental changes. The formation of Smart Community is based on the ubiquitous network connection. Under the effect of network technology, the life, work and study of citizens are all included in the networked activities. From government service to ecommerce and distance education, all belong to the service scope of Smart Community [1]. Subsequently, since 1997 the Communication International Center began to focus on the construction and promotion of Smart Community, and put forward the concept of government, related industries, educators and citizens collaborating to participate in community construction, but it did not attract wide attention.

By the end of 2008, IBM put forward the concept of smart earth, which sparked a smart revolution sweeping the world. One year later, IBM further put forward the concept of smart city, which kicked off the practice of smart city all over the world. Thanks to the small scale of communities in the city, it is easy to carry out the test and practice there, so it becomes an important application area of smart city, and construction booms of Smart Community are set off globally.

As the cognition and positioning of the scholars of smart community are not uniform and the development direction and construction emphasis they determined are different, so the Smart Communities in reality are quite different with their own characteristics, instead of having a unified model. But in general, Smart Communities all have a data center and a set of intelligent processing system, and they all need to provide various convenient services including government affairs, business and intelligent home for the community residents, of which the core is using information technology to integrate different systems and different services[2]. In terms of framework, Smart Community generally includes the entity community and the virtual community service platform. The personnel information, geographic information, building information, event information and all kinds of organization information of the entity community are informationized and digitized through the data center, and then enter the various types of databases in the virtual community service platform. The virtual community service platform uses the cloud computing technology to analyze the data in all kinds of databases intelligently, and then provides comprehensive services such as government affairs, business, transportation, medical treatment and entertainment through the corresponding intelligent service terminals to meet the needs of community residents. 
In conclusion, this paper holds that Smart Community is a modern community form that takes the actual needs of community residents as a starting point and new generation of information technology as a means and integrates the various types of service resources existing in the community to provide the community residents with various kinds of convenient services like government affairs, business, culture and entertainment, distance education, family health care and mutual assistance and so on.

\section{B. The Characteristics of the Smart Community}

1) Putting people first: The purpose of building a smart community is to make the residents' life more secure, convenient and comfortable, and become more civilized, and the community become more civilized and harmonious by using modern science and technology to fully meet the diversified, humanized and personalized material needs and spiritual needs of the community residents, so putting people first is an important feature of Smart Community.

2) The interconnection and perception of human and things: Smart Community can comprehensively sense the information of every person and thing in the community through the Internet of Things composed of the sensor and intelligent equipment all around, and use the mobile Internet and intelligent information terminal to achieve the interconnection between human and things through the analysis made by cloud computing.

3) Synergy of "smart" and "intelligence": "Smart" refers to the automation and intelligenization at technical level; "intelligence" refers to the creativity at spiritual level[3], of which the core is innovation. Smart Community is not only the intelligent community with a variety of intelligent systems and terminal equipment to make the lives of community resident more convenient, but also the wise community, which can provide agile, active and accurate services for the community residents and optimize the lifestyles of community resident.

4) Sustainable development: The information technology that Smart Community is established based on continues to develop, the needs of service objects of community change constantly, and the requirements of management of higher-level institutions on the community continue to improve. In order to adapt to the development of technology and the change of management, Smart Community must continue to self-optimize, self-improve, and achieve sustainable development.

\section{PROBLEMS IN THE CONSTRUCTION OF SMART COMMUNITY IN CHINA}

In recent years, in the process of promoting the construction of Smart Community all over our country, they have carried out the pilot work of Smart Community and achieved some success, but there are also some problems that cannot be ignored.

\section{A. Lack of Unified Planning and Deployment and Difficulties in Forming the Situation of Overall Advance}

Smart Community is a new concept developed based on the concept of smart city. The government departments, enterprises, communities, residents and other subjects have different understanding of Smart Community from their own point of view, so they take different approaches in practice, leading to the lack of a unified planning and deployment in the construction of the Smart Community and parallel track of the main body of construction. On the other hand, due to the short development period of Smart Community, it has not yet formed a mature and unified Smart Community structure, and there is no mandatory uniform standard in data collection and equipment access, which is not conducive to the promotion and integration of Smart Community, so it is hard to form the situation of overall advance.

\section{B. Immature Application Technology and Low Degree of Integration of Service Systems}

At present, construction of Smart Community in China has just started, so it lacks perfect technology and experience. Although the new generation of information technology has rapidly developed, it has not been widely promoted and skillfully used in the construction of Smart Community, leading to the low intelligence level of community service. In addition, since the time of construction of Smart Community pilot construction is short, it has not yet formed unified construction standards and corresponding industry standards, so the systems cannot share between each other and various interfaces are too complex to achieve effective integration. Precisely because of the above reasons, community service systems work for themselves without a unified standard and the integration degree is too low to form a strong, unified, widely used comprehensive information service platform of the community.

\section{Serious "Information Island" and Repeated Construction}

"Information Island" is an important problem encountered in the development of information society in recent years. Its concrete connotation refers that different computer application systems can not realize the integration with each other in function and sharing and communication in information and disconnect from each other in business process and application. There is no horizontal and vertical links between the construction subjects of Smart Community in our country, so they cannot achieve effective information exchange, leading to serious information island and repeated construction. First of all, urban administrative departments in China are fragmented and managed separately, so various departments lack horizontal links. The city management system is not conducive to the construction of a unified information management platform. Secondly, at present, the construction of Smart Community in our country lacks the unified standard since the different enterprises involved in the construction of Smart Community work for them to develop and construct system independently, which is not conducive to the sharing of information resources and inevitably cause repeated construction. 


\section{Single Construction and Operation Mode}

China advocated "government lead, industry guide, and business and society participate jointly" in the construction of Smart Community, but in reality the enthusiasm of enterprises and institutions and social organizations involved in the construction of Smart Community is not high and currently the government-led Smart Communities still take the lead. The participation degree of social forces is not high, so it is difficult to form a diversified social participation mechanism by relying solely on the leading role of government departments. The entrance channels of social capital are blocked, and there are deficiencies in construction of Smart Community. For example, in the aspect of investment in key projects of Smart Community in China, the proportion of government investment and social investment is serious imbalanced, since the former accounts for $61 \%$ of the total investment, while the latter accounts for only $23 \%$ [5].

\section{E. Lack of Professional Talents}

Smart Community applies a large number of modern information technologies, so its management and service mode are quite different from those of the traditional community, which need a large number of general staff with applied knowledge of modern information technology. However, the existing staff in our community generally has low education level, lack professional information knowledge, and cannot fit the management services work of Smart Community. At the same time, due to the short development time of Smart Community, imperfect talent introduction and incentive mechanism, it is difficult to attract the versatile talent who not only master the technology but also know management to participate in the construction of Smart Community.

\section{COUNTERMEASURES OF PROMOTING THE CONSTRUCTION OF SMART COMMUNITY}

To promote the further development of the construction of Smart Community, form the situation of overall advance, we must recognize the problems, clear ideas, and take targeted measures.

\section{A. Strengthen Planning Coordination and Standardized Construction}

The construction of Smart Community is a systematic project. The central government should strengthen the toplevel design, unify the guiding ideology, make clear the concept of construction, determine the direction, goal and key construction content of Smart Community and develop the technical standards; the local government should follow the trend of the times, actively participate in the construction of Smart Community, and make comprehensive planning, deployment and coordination of the construction of Smart Community [6].

In the process of planning and construction of Smart Community, the local government should establish an efficient coordination and cooperation mechanism break the current situation of difficult coordination among departments and reform the situation of fragmented administration and separate governance, to achieve communication and collaboration among departments and avoid inefficient repeated construction under the leadership of relevant departments.

In the process of building a comprehensive information service platform of Smart Community, we must play the regulatory function of local government, achieve the crosssystem cooperation and cross-domain sharing of various technical resources and information resources under the guidance of local government, change the information island phenomenon, and realize the effective integration and optimal configuration of resources.

\section{B. Speed up the Construction of Network Infrastructure}

Construction of Network infrastructure is the basis of the realization of Smart Community. For the current situation of the imperfect network infrastructure in Smart Community, we should use the new generation of information technology to speed up the construction of perceptual and communication network facilities of community, and "increase the availability and convenience of community residents to obtain services" [7].

We can adopt the information collection technology, wireless positioning system, radio frequency identification technology and other internet of things technology to promote the perceptual network construction of pipeline facilities including water supply, power supply, gas supply, heat supply and so on, perceptual network construction of community security like video surveillance, perimeter perception and visual access and perceptual network construction of home lighting and household appliances, and thus achieve the intelligent regulation of "water, electricity, gas and heat" in the community, intelligent monitoring on community security and intelligent adjustment of home life.

We should also use the new generation of communication technology to promote the construction of wired network and wireless network in the community and build a communication network covering the entire community. First of all, we can improve the speed of Internet through the optimization and upgrading of wired networks. For example, we can popularize fiber within China. Second, we should expand the coverage of the network, so that more users can enjoy the convenience of network. For example, we can speed up the construction of wireless LAN and $4 \mathrm{G}$ network.

\section{Promote the Construction of Smart Community with the Construction of Smart City}

Smart Community is the basic unit of smart city as well as an important pilot area of construction of smart city. Therefore, the construction of smart community should be carried out under the overall framework of construction of smart city and driven by the construction of smart city, so we need to promote the application system of smart city to extends to the community and thus improve the service area of Smart Community. 
First of all, we can broaden the coverage area of urban smart security system and set up intelligentized monitoring and sensing equipment in the community in accordance with the requirements of intelligent security to build an integrated comprehensive security system; secondly, we should realize the effective connection between urban smart health care system and community hospitals through establishing resident electronic health records and other basic database to achieve information sharing and remote video treatment; thirdly, we can set up a variety of smart government service terminals in the community service center, so that residents can easily and quickly get the various kinds of public service of government without going out of the community; finally, relying on the development results of smart business and smart traffic of smart city, we can build life service platform of the community to meet the living needs of residents including shopping, catering, entertainment, and transportation and so on.

\section{Adopt Different Construction and Operation Mode according to Local Conditions}

There are great differences among cities in China in the level of economic development, science and technology development, and network infrastructure construction, so in the construction of smart city, we should proceed from reality and use different construction and operation mode.

In the small and medium-sized cities with relatively weak economic base, imperfect network infrastructure and the low level of scientific and technological development, the construction of smart community should adopt the construction and operation mode of "government lead and enterprises participate". Government should make unified planning, determine the construction goals and construction priorities, introduce preferential policies and provide financial support to attract enterprises to participate in the construction of smart city.

In the second and third tier cities with better economic base, relatively perfect network infrastructure and certain scientific research strength, construction and operation mode of "government + business + citizen" can be adopted. The government can allow enterprises to participate in infrastructure construction, service platform maintenance and operation and provision of various community services through the method of bidding to provide all-round supervision and management for the access and participation of enterprises. Residents can express their demands, opinions and suggestions through the participation mechanisms of forum, hearings, and councils and social media of community sites, microblog and WeChat to participate in the construction of Smart Community.

In the first-tier cities with a large number of scientific research institutions and high-tech enterprises and developed economy, construction of Smart Community can adopt the construction and operation mode of "enterprise investment and construction dominate and government cooperation serve as auxiliary". Enterprises use their own funds, talents and technological advantages and independent investment to construct, operate and manage, while the government introduces corresponding supporting policies and regulations to assist enterprises to complete the construction of Smart Community.

\section{E. Strengthen Personnel Training}

The construction and effective operation of Smart Community requires a large number of specialized talents and management personnel, so strengthening the training of talent is essential for the development of Smart Community.

The state should integrate various research and development forces, to carry out in-depth research on the key areas and key technologies of the construction of Smart Community and train a group of key talents who master the core technology. All kinds of colleges and universities and vocational training schools should strengthen the discipline construction and students training related to Smart Community to provide various kinds of professional talents for sustainable development of Smart Community; they can strengthen the on-the-job training of community staff through a variety of regular and irregular information technology special training and managerial knowledge special training to improve the information technology skills and level of comprehensive management of community staff; they can also complete the incentive mechanism and raise the welfare of community staff to attract outstanding college students, grassroots civil servants and other talents to work in the community.

\section{CONCLUSION}

The Smart Community is the hot fields of the pilot and application of promoting the smart city in our country, as well as the important direction of the development and construction of future urban community. However, it can be found that there are still many problems through synthesizing the construction status of Smart Community in China. Only by strengthening the top-level design, unifying technical standards, planning and deployment, improve the network infrastructure, promote the construction of Smart Community by construction of smart city, and adopt appropriate construction and operation mode and cultivate professionals according to local conditions, can we truly promote the construction and development of Smart Community in China.

\section{REFERENCES}

[1] Communications ICF. The SmartCommunity Concept [EB/OL]. 2011-11.http://www.smartcommunities.org/.

[2] Shen Yue, Chai Yanwei, Ma Xiujun. The Concept, Pattern and Structure of Humanistic Oriented Smart Community, Modern Urban Research, 2014(10): 13-17.

[3] Chen Gang. The Development of construction of Smart Community in China, Information Technology and Informatization, 2016(10): 2628.

[4] Jiang Junjie From Tradition to Smart: Dilemma and Reconstruction of Public Service Model of Urban Community in China. Zhejiang Academic Journal, 2014 (04): 117-123.

[5] Xiu Fangan. Smart Community: Top-level Design Case (PPT[EB/OL].2015-03-

12.http://www.haokoo.com/else/2047837.html. 
[6] Li Guoqing, Li Yi. Predicament and Outlet of Construction of Smart Community in China Journal of Guangzhou University (Social Science Edition), 2015 (12): 67-71.

[7] Liu Jun. Research on the development strategy of service in Smart Community. Modernization of Management, 2012 (6): 46-48. 